\title{
Biogenesis and function of macrocyclic spermine alkaloids
}

\author{
Lenka Nezbedová, Konstantin Drandarov, Nathalie Deschamps, Christa Werner, \\ and Manfred Hesse* \\ Organisch-chemisches Institut der Universität Zürich, Winterthurerstrasse 190, 8057 Zürich, \\ Switzerland \\ E-mail: mtbohley@oci.unizh.ch
}

\section{Dedicated to Professor T. R. Govindachari on the occasion of his $85^{\text {th }}$ birthday \\ (received 08 May 01; accepted 17 Oct 01; published on the web 25 Oct 01)}

\begin{abstract}
The results of the recent studies on the biogenesis of the macrobicyclic spermine alkaloid aphelandrine are reviewed. The possible role of aphelandrine and its precursors prelandrine and dihydroxyverbacine in the cell metal ion homeostasis (uptake, turnover and transport of metal ions) is discussed.
\end{abstract}

Keywords: Polyamine alkaloids, aphelandrine, biosynthesis, cytochrome P-450, phenol oxidation, metal complexation

\section{Introduction}

The natural polyamines putrescine (1), spermidine (2) and spermine (3) are ubiquitous bases reported to have several important functions in animals, plants and microorganisms. They are involved in processes of transcription and translation in protein synthesis and influence growth and development (cell division, differentiation, embryogenensis, etc.). In plants their involvement in organ development, flowering, fruit ripening, senescence and stress responses is reported. ${ }^{1}$

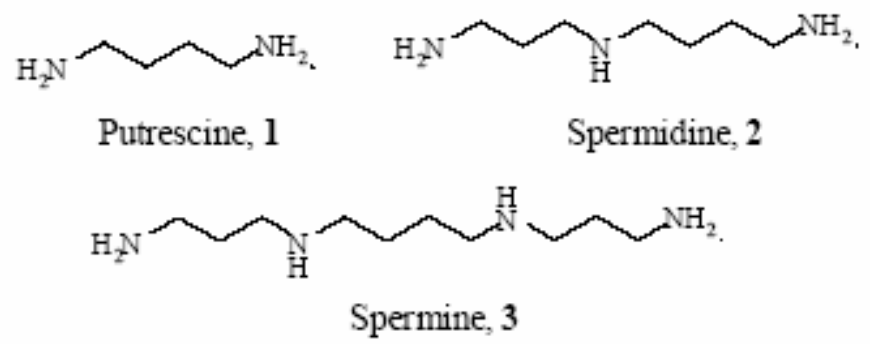


Polyamines occur in nature not only as free aliphatic bases but are often conjugated with phenolic acids, fatty acids or amino acids. In animal and bacterial systems they can form part of peptides (glutathionylspermidine), amino acids (putreamine) or antibiotics (bleomycin, tallysomycin). In plants the amides of polyamines with hydroxycinnamic acids such as ferulic, $p$ coumaric and caffeic acids are widespread and appear to be the main phenolic constituents in the reproductive organs. Their role in the physiological processes of flowering and seed development as well as in defense mechanisms against viral and fungal infections are postulated. ${ }^{2}$ Additionally, due to their high UV-absorbing properties their importance as photoprotectants of the pollen gene material was proposed. ${ }^{3}$

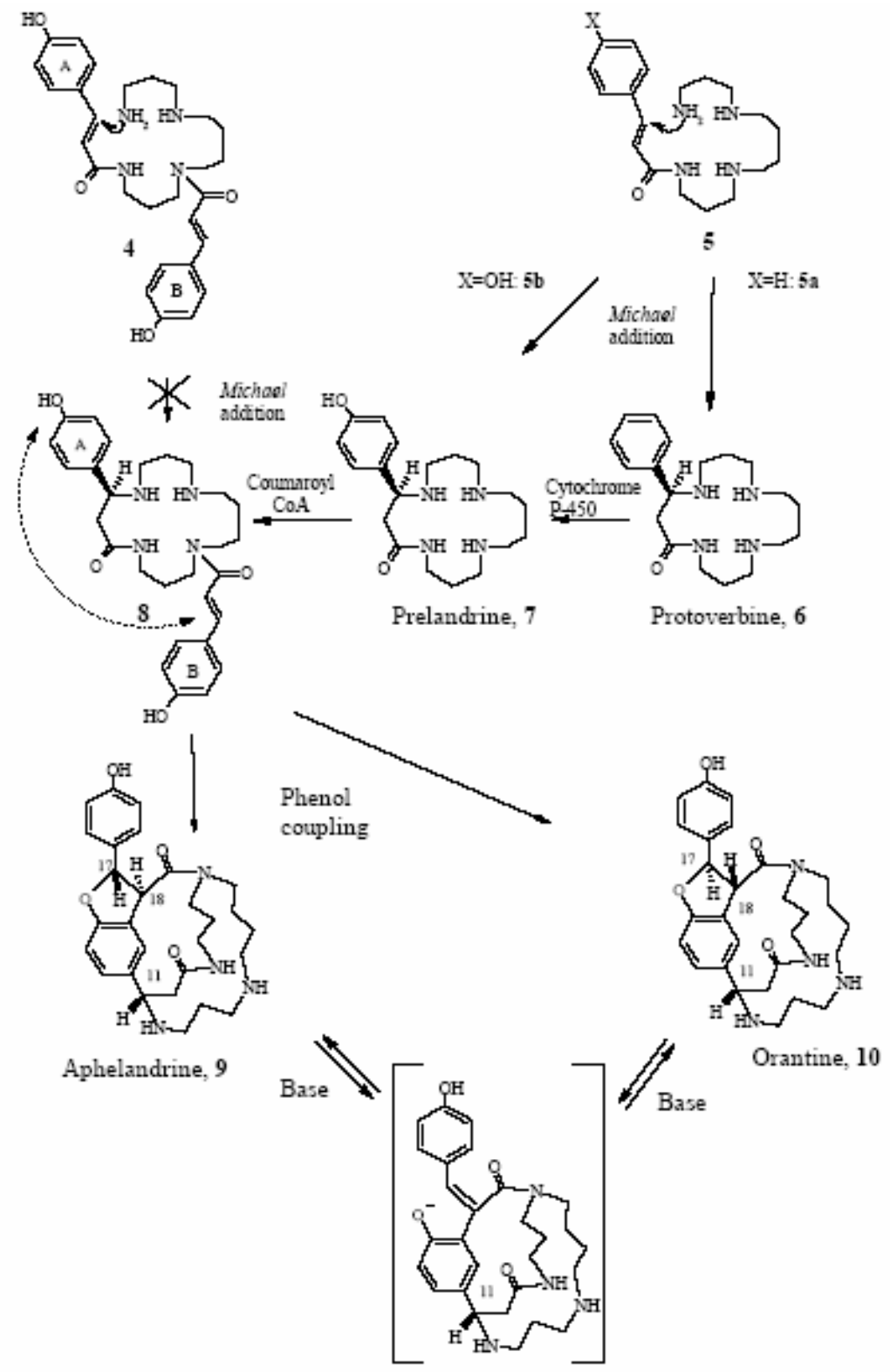

Scheme 1. Possible biochemical pathways leading to the alkaloids aphelandrine (9) and orantine (10). 
The naturally occurring polyamine conjugates are often linear molecules $(4,5$, Scheme 1$)$ but also polyazamacrocyclic derivatives $(\mathbf{6}-\mathbf{1 0}$, Scheme 1$)$ have been isolated from different plant families and show a broad structural complexity. They share a common feature: besides the polyamine chain they contain one or two carboxylic acid moieties, often cinnamic acid, $p$ coumaric acid and/or its methoxylated derivatives.

In our particular interest is a rare class of macrobicyclic spermine alkaloids identified in Aphelandra plants (Acanthaceae, Scrophulariales). The main alkaloids of this genus, aphelandrine (9) and its diastereoisomer orantine (10), were isolated from the roots of different Aphelandra species. ${ }^{4,} 5$ In addition, orantine (ephedradine A, 10) was isolated from Chaenorhinum minus, Schweinfurthia papilionacea (both Scrophulariaceae), and from Ephedra sp. (Ephedraceae). ${ }^{6-8}$ The pharmacological important ephedradines have the same stereochemistry as orantine (10) and they were identified in the roots of Ephedra sp. ${ }^{8-10}$
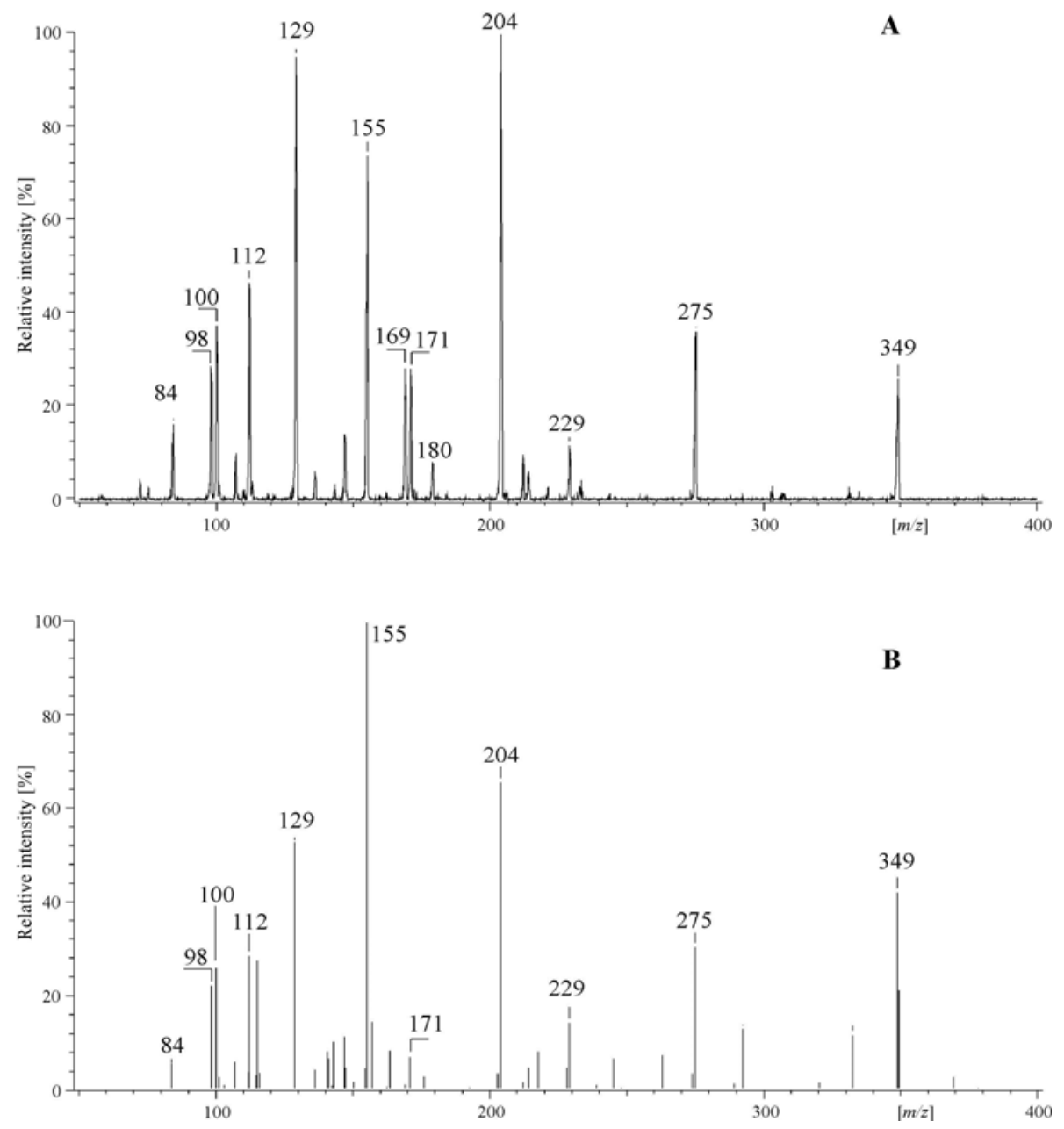

Figure 1. MS/MS results of synthetically prepared prelandrine (7) as a standard (A) and prelandrine (7) identified in the root $\operatorname{extract}(\mathbf{B})$. The synthetically prepared prelandrine was used as a fingerprint. 


\section{The aphelandrine biosynthesis}

Until recently only small information on the biosynthesis of polyamine alkaloids was available. The structure of this type of alkaloids suggests a biosynthetic pathway connecting building blocks like hydroxycinnamic acids, spermine (3), spermidine (2) and/or putrescine (1) by enzyme reactions including acylation, Michael addition and oxidative cyclisation. Preliminary investigations on the biosynthesis of aphelandrine (9) with ${ }^{14} \mathrm{C},{ }^{3} \mathrm{H}$-labelled putrescine (1), spermidine (2) and spermine (3) on whole Aphelandra plants showed that the polyamines were incorporated. ${ }^{11}$ Additionally the hydroxycinnamoyl-CoA transferases, the enzymes catalyzing the transfer of hydroxycinnamoyl residues to polyamines were detected in Aphelandra plants. ${ }^{12}$ In the case of lunarine, a macrocyclic spermidine alkaloid from Lunaria annua, the incorporation of the ${ }^{14} \mathrm{C}$-labelled coumaroyl spermidine indicates that hydroxycinnamoyl amides are precursors of this type of alkaloids. ${ }^{13}$ But knowledges about the enzymes involved in the further steps of cyclization or acylation were completely lacking until recently.

The biosynthesis of aphelandrine (9) and orantine (10) proceeds presumably by one of the pathways shown in Scheme 1. Either mono-or dicoumaroylspermine is cyclized to form the monocyclic intermediates $\mathbf{6}, \mathbf{7}$, and $\mathbf{8}$. In both cases the terminal precursor is postulated to be $(S)$ dihydroxyverbacine (8). This assumption is based on the established distribution of monocyclic spermine alkaloids like verbacine and its derivatives in plants (Fig. 1), which are analogous to the here expected terminal precursor $\mathbf{8}$ of aphelandrine (9). ${ }^{14}{ }^{15}$ This fact suggests that this metabolic reaction sequence, occurring in different plant families, is widely spread in nature. For this reason aphelandrine is proposed to be formed from 8. The last, crucial step in the biosynthesis is than a diastereoselective intramolecular phenol oxidative coupling between the $p$ coumaroyl acid units of $(S)$-dihydroxyverbacine (8) to form the benzofurane ring of aphelandrine (9). Since microsomal bound cytochrom P-450 enzymes are shown to participate in highly regioand stereoselective phenol coupling reactions in benzylisoquinoline alkaloids, ${ }^{16}, 17$ it was expectible, that an enzyme of this type might be responsible for the phenol coupling in the biosynthesis of aphelandrine (9).

\section{1. 1. The asymmetric synthesis of the [D8]-labelled (-)-(S)-dihydroxyver-bacine (2)}

To avoid a possible interference with the endogenous aphelandrine (9), present in the plant material, the labelled (S)-D8-dihydroxyverbacine (25) was synthetically prepared as shown on Scheme $2 .^{18}$

\section{1. 2. Transformation of [D8]-labelled (-)-(S)-dihydroxyverbacine to [D8]-aphelandrine by phenol coupling in presence of microsomes from $A$. squarrosa}

Phenol oxidative coupling of the intermediate $(S)$-dihydroxyverbacine (8) was studied in the microsomal fraction from the 12 weeks old roots of $A$. squarrosa. The incubation mixture for the attempted phenol coupling reaction contained (S)-D8-dihydroxyverbacine (25), NADPH, and microsomal suspension. The enzymatic mixture was analyzed by on-line coupled HPLCUV(DAD)-ESI (electrospray ionization) MS and by HPLC-UV(DAD)-ESI-MS/MS. ${ }^{19}$ 


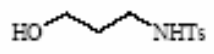

12

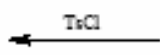

$\mathrm{HO}+\mathrm{m}+\mathrm{NHH}_{2}$

11
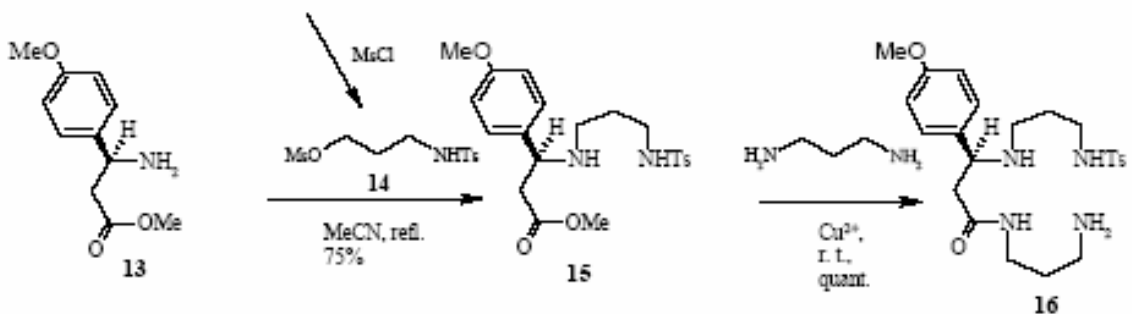

16

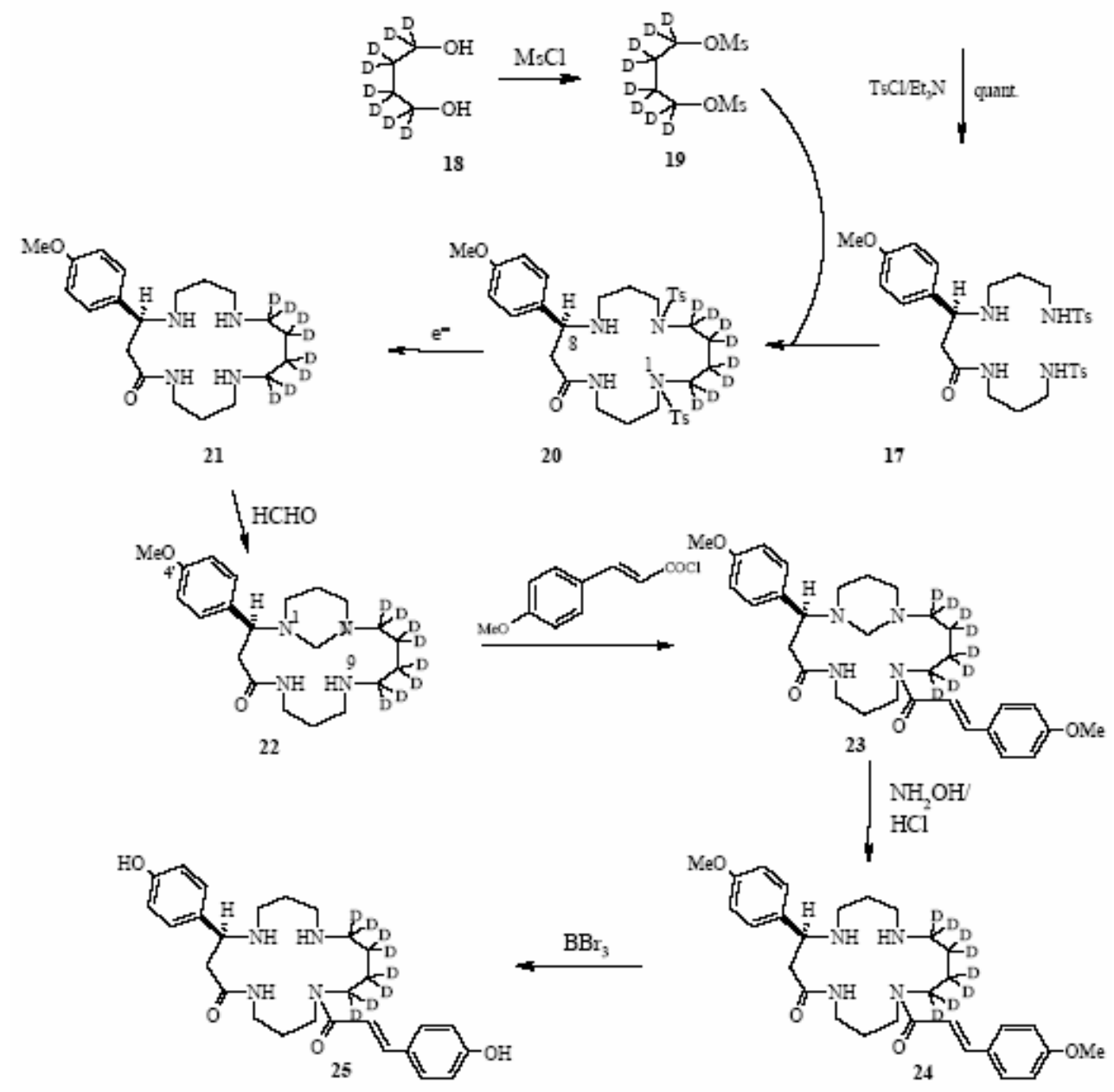

Scheme 2. The synthesis of the labeled (S)- $\mathrm{D}_{8}$-dihydroxyverbacine (25).

In the ESI-MS a $\left[M+\mathrm{H}^{+}\right.$quasi molecular peak at $\mathrm{m} / \mathrm{z} 501$, corresponding to $\mathrm{D}_{8}$ aphelandrine (26) was detected with exactly the same retention time (11.3 $\mathrm{min})$ as the natural aphelandrine (9). The MS/MS showed the fragmentation pattern corresponding to aphelandrine (26), fully 
deuterated in its putrescine $\mathrm{C}_{4} \mathrm{H}_{8}$ chain. The fragment ions of $9(\mathrm{~m} / \mathrm{z}$ 493) and labelled enzymatically formed $26(\mathrm{~m} / \mathrm{z} 501)$ were identical or differed by $8 \mathrm{amu}$ (Fig. 2). Thus, it was shown that the labelled precursor $(S)-\left(\mathrm{D}_{8}\right)$-dihydroxyverbacine (25) was enzymatically transformed by the microsomal fraction into $\left(\mathrm{D}_{8}\right)$-labelled aphelandrine $(\mathbf{2 6}){ }^{20}$

That aphelandrine synthase, the enzyme catalyzing the last phenol oxidative coupling step, is a membrane bound cytochrome P-450 enzyme was proven by several key criteria. Only some shall be mentionned here for details see reference 20 .

The formation of aphelandrine was strictly dependent on $\mathrm{O}_{2}$ as well as on NADPH. When NADPH was substituted with NADH less then $10 \%$ of the activity was detected. When the reaction mixture was bubbled with $\mathrm{N}_{2}$ gas to displace $\mathrm{O}_{2}$ only $5 \%$ of the enzyme activity was detected. An absolute requirement for oxygen was also demonstrated by removing $\mathrm{O}_{2}$ from the assay through the addition of the glucose/glucose oxidase/catalase system. ${ }^{21}$

In Aphelandra sp. orantine (10) is almost always present as a minor alkaloid together with aphelandrine (9). In principle, the biogenesis of orantine (10) should follows the same reaction sequence as postulated herein for aphelandrine (9). The HPLC behavior of orantine (10) $(\mathrm{Rt}=$ $2.3 \mathrm{~min}$ ), used as standard, is completely different then that of aphelandrine (9) $(\mathrm{Rt}=11.3 \mathrm{~min})$. No orantine (10) was detected in the HPLC/MS analysis of the chloroformic extracts from incubates. This indicates that $(S)$-dihydroxyverbacine (8) was diastereoselectively transformed to aphelandrine (9) by aphelandrine synthase (cytochrome P-450) and orantine (10) should be the product of an iso-enzyme. It was established earlier, that under strong basic conditions aphelandrine undergoes ring opening-closure isomerization to orantine $(\mathbf{1 0})^{22}$ (Scheme 1). Under the used mild acid/base conditions of isolation an artificial isomerization of aphelandrine (9) to orantine (10) seems unlikely. But, the possibility of an enzymatic isomerization of aphelandrine (9) to orantine (10) in cells can not be ruled out.

\section{2. Biosynthetic precursors of dihydroxyverbacine}

Dihydroxyverbacine (8) can be directly macrocyclized from 1,5-dicoumaroylspermine (4) by Michael type addition (Scheme 1, left). This assumption is based on the established large distribution of mono-, di-and polycinnamoyl substituted polyamines as natural secondary metabolites in the plant kingdom and by the fact that $\mathrm{N}(1), \mathrm{N}(10)$-bis ( $p$-coumaroyl)-spermidine is involved in the biosynthesis of the macrocyclic spermidine alkaloid lunarine. ${ }^{13}$ Moreover, a large group of similar compounds, including coumaroylspermidines has been isolated from the anthers of different Aphelandra species. ${ }^{23}$

According to the second possibility (Scheme 1, right), the key intermediate in the biosynthesis of aphelandrine (9) has been proposed to be $(S)-4^{\prime}$-hydroxyprotoverbine

(7) which is formed from 1-cinnamoylspermine (5a) or 1-coumaroylspermine (5b) derivative via macrocyclization by Michael type addition. The following acylation step (coumaroyl CoA, corresponding acyl tranferase) of (S)-4'-hydroxyprotoverbine (7) would yield the terminal precursor $(S)$-dihydroxyverbacine (8).

The similarly constituted alkaloids protoverbine (6) (4'-unsubstituted analogue of prelandrine, 5) and buchnerine (7) (O-methylated analogue of prelandrine, 5) were isolated 
earlier from different Verbascum species (Scrophulariaceae) $)^{14,15}$ and Clerodendrum buchneri (Verbenaceae). ${ }^{24}$

Subsequently enzymatic studies led to the detection of spermine (3) and spermidine (2) hydroxycinnamoyl transferases in the cell free extract from the stems of Aphelandra tetragona. ${ }^{12}$ But the comparison of the time course of the aphelandrine (9) accumulation in the roots with the time course of spermine hydrocinnamoyl transferase activities in the stems gives no clear answer to the question whether the hydroxycinnamic acid amides formed in the stems have any relation to the biosynthesis of aphelandrine (9). However, all attempts to detect the above-mentioned 1,5dicoumaroylspermine (4) or any of its homologs in the root extracts of A. squarrosa have been unsuccessful. Thus, its role as precursor remains uncertain.

\subsection{Prelandrine, the key step intermediate in the biosynthesis of aphelandrine}

A method allowing the extraction of more polar alkaloids, and analysis by the highly sensitive on-line coupled HPLC/APCI-MS technique paved the way leading to the decision concerning the possible pathway. Analysis of the alkaloid extract from 12 weeks old roots of $A$. squarrosa shown besides the known alkaloids an additional peak with the quasi molecular ion $[M+\mathrm{H}]^{+}$at $\mathrm{m} / \mathrm{z}$ 349. This mass corresponds to the intermediate (-)-(S)-4'-hydroxyprotoverbine (7) proposed in the second, above mentioned, pathway (Scheme 1). To prove the structure of 7,(-)-(S)-4'hydroxyprotoverbine (7) was synthesized from the synthetically prepared $(-)-(S)$-buchnerine ${ }^{25}$ by its O-demethylation with $\mathrm{BBr}_{3}$. The data obtained by HPLC-UV (DAD)/APCI-MS and MS/MS measurements show the identity between the synthetic and the natural products. ${ }^{26}$ The MS/MS experiment showed an identical fragmentation pattern for the synthetic and the natural compound (Fig.1). Since (-)-(S)-4'-hy-droxyprotoverbine (7) is a natural product it was named prelandrine (7) (Scheme 1). The presence of prelandrine (7) in the investigated root extracts of A. squarrosa suggests its possible key role in the biogenesis of aphelandrine (9) and favored the second mentioned possible pathway (Scheme 1).

In the case that $\mathrm{N}(1)$-cinnamoylspermine (5a) is the substrate for the macrocyclization by Michael addition, an aromatic hydroxylation step from 6 to 7 could be expected. In plant tissue hydroxylations and a broad range of oxidative biochemical transformations are catalyzed by membrane bound cytochrome P-450 depending oxygenases. The microsomal fraction of young Aphelandra roots was therefore tested for its capacity to hydroxylate protoverbine (6) to form prelandrine (7). After microsomes were incubated with the synthetically prepared $(-)-(S)$ protoverbine (6) in the presence of NADPH the hydroxylated derivative prelandrine (7) was detected by on-line coupled HPLC/UV (DAD)/APCI-MS. ${ }^{26}$ The structure was proven using the synthetically prepared prelandrine (7) as reference. The enzyme catalyzing this aromatic hydroxylation was identified as a membrane-bound cytochrome P-450 enzyme, requiring $\mathrm{NADPH}$ and $\mathrm{O}_{2}$ by the same key criteria as for the aphelandrine synthase. Thus, two membrane bound cytochrome P-450 dependent oxygenases were detected in microsomes of young Aphelandra roots: one catalyzing an oxidative cyclization and another catalyzing an aromatic hydroxylation.

Although protoverbine (6) is a precursor for prelandrine (7), any traces of it were detected in 
the studied extracts from the roots of A. squarrosa. Therefore the question whether prelandrine (7) derives directly from coumaroylspermine (5b) by macrocyclization or from protoverbine (6) by aromatic hydroxylation stays open.

\section{The metal ion complexation abilities, possible aim of the biosynthetic transformation sequence: monocoumaroyl (monocinnamoyl)-spermine $\rightarrow(-)-(S)$-prelandrine $\rightarrow(-)-(S)$ - dihydroxyverbacine $\rightarrow$ aphelandrine}

The naturally occurring linear polyamines putrescine (1), spermidine (2) and spermine (3) are strong bases and in the neutral physiologic $\mathrm{pH}$ value they are fully protonated. Moreover, they possess strong chelating ability for transition metal ions. In general, the macrocyclization of the linear polyamines increases their affinity for cations $\left(\mathrm{H}^{+}\right.$or metal $\left.\left(\mathrm{M}^{+}\right)\right)$as a result of increasing of the intraanular electron density due to conformational restrictions, phenomenon known as "macrocyclic effect". Depending on the ring size and the number of N-atoms, the macrocyclic polyamines show remarkable selectivity for different guest cations.

The complexation properties of the linear monocinnamoyl spermine 5, the monocyclic polyazamacrolactam protoverbine (6), and the macrobicyclic aphelandrine (9) were studied recently by ESI-MS techniques ${ }^{27}$ While the linear monocinnamoyl spermine 5 forms complexes with all $d$-block metal cations $\left(\mathrm{Mn}^{2+}, \mathrm{Co}^{2+}, \mathrm{Ni}^{2+}, \mathrm{Cu}^{2+}\right.$ and $\left.\mathrm{Zn}^{2+}\right)$, the naturally occurring polyazamacrocycle protoverbine (6) posseses higher ligand selectivity showing complexation only with $\mathrm{Ni}^{2+}$ and $\mathrm{Cu}^{2+}$. These specific ligand properties suggest possible biological function of the monoacylated spermine 5 and the monocyclic polyazamacrolactams protoverbine (6) and prelandrine (7) as participants in the cell metal ions homeostasis (uptake, turnover and transport of metal ions) in the plant tissues.

It is noticeable that the bicyclic polyamine aphelandrine (9) is completely devoid of complexation ability, obviously due to the sterically hindered molecular cavity. The biological function of aphelandrine (9) in the plant cells is still unknown. The highest accumulation of aphelandrine (9) in the Aphelandra tetragona roots has been found to be $7 \mathrm{mg} \mathrm{g}^{-1}$ and $9 \mathrm{mg} \mathrm{g}^{-1}$ dry wt 16 and 26 weeks after planting. ${ }^{28}$ This high accumulation of aphelandrine (9), a complex molecule possessing four nitrogen atoms and consuming high energy ressources for its biosynthesis strongly suggests its importance in the physiology of the plant. There are some recent evidences that aphelandrine (9) plays a role in the interactions between plant roots and endophytic or pathogenic fungi. ${ }^{29}$ 

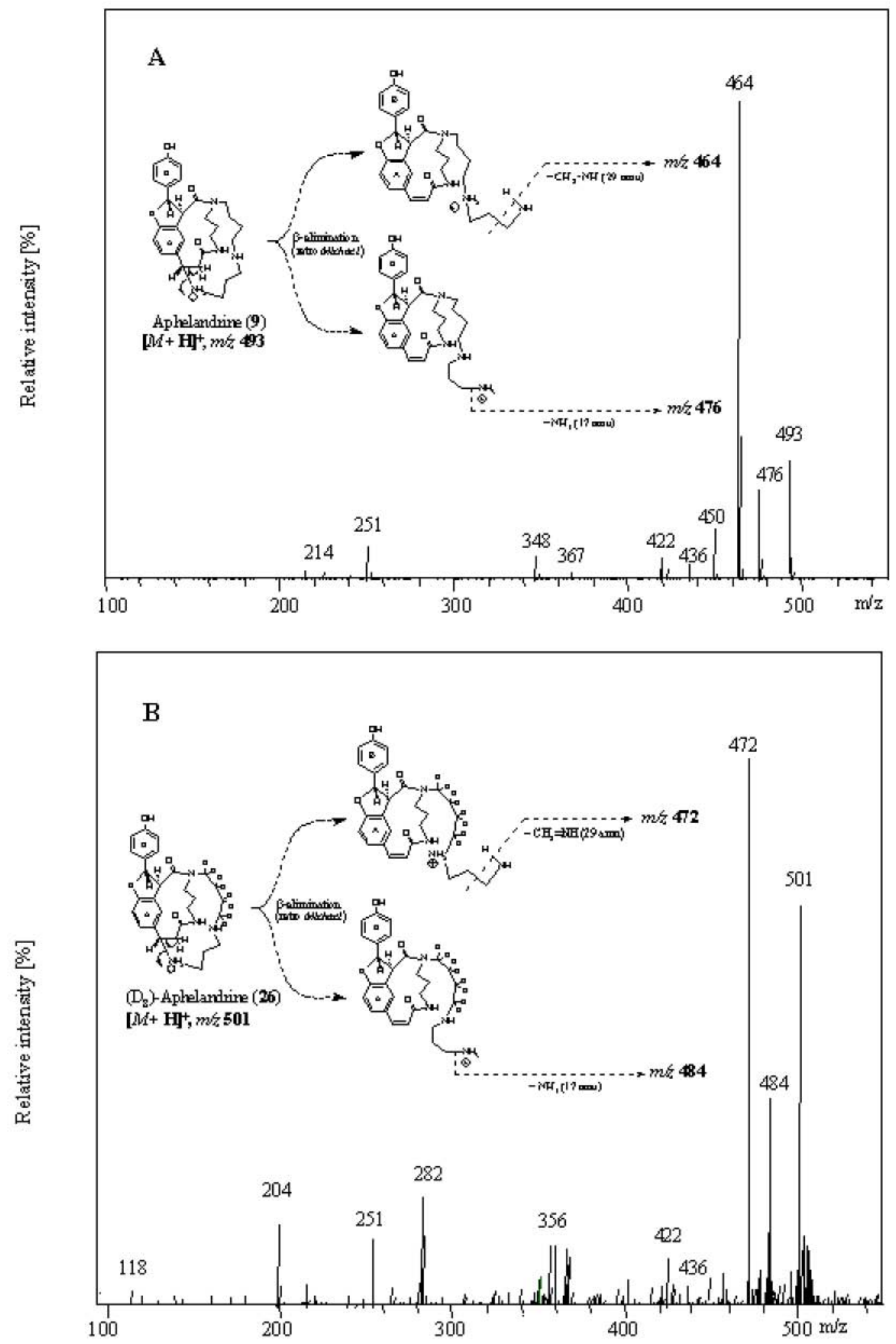

Figure 2. HPLC-ESI-MS/MS of native aphelandrine (9) (A, $\mathrm{m} / \mathrm{z} 493)$ and enzymatically formed (D8)-aphelandrine (26) (B, $\mathrm{m} / \mathrm{z} 501)$. The enzymatic product was detected in the aphelandra synthase assay containing microsomes from $A$. squarrosa and (S)-D8-dihydroxyverbacine as a substrate. 


\section{Acknowledgements}

The authors are grateful for the financial support of the Swiss National Science Foundation and the Dr. Helmut Legerlotz-Stiftung.

\section{References}

1. Bouchereau, A.; Aziz, A.; Larher, F.; Tanguy, J. M. Plant Science 1999, 140, 103.

2. Flores, H. E.; Martin-Tanguy, J. In "Biochemistry and Physiology of Polyamines in Plants", Slocum, R. D.; Flores, H. E., Ed.; CRC Press Inc. 1991; pp 57-77.

3. Youhnovski, N.; Bigler, L.; Werner, C.; Hesse, M. Helv. Chim. Acta 1998, 81, 1654.

4. Bosshardt, H.; Guggisberg, A.; Johne, S.; Hesse, M. Pharm. Acta Helv. 1978, 53, 355.

5. Dätwyler, P.; Bosshardt, H.; Bernhard, H. O.; Hesse, M.; Johne, S. Helv. Chim. Acta 1978, 61, 2646.

6. Zhu, J-P.; Hesse, M. Planta Med. 1988, 5, 430.

7. Ahmad, V. U.; Sultana, V. J. Nat. Prod. 1990, 53, 1162.

8. Tamada, M.; Endo, K.; Hikino, H.; Kabuto, C. Tetrahedron Lett. 1979, 873.

9. Hikino, H.; Konno, C.; Takata, T.; Tamada, M. Chem. Pharm. Bull. 1980, 28, 2900.

10. Hikino, H.; Ogata, M.; Konno, C.; Sato, S. Planta Med. 1983, 48, 290.

11. Papazoglou, G.; Sierra, J.; Homberger, K.; Guggisberg, A.; Woggon, W.-D; Hesse, M. Helv. Chim. Acta 1991, 74, 565.

12. Hedberg, C.; Hesse, M.; Werner, C. Plant Science 1996, 113, 149.

13. Sagner, S.; Shen, Z. W.; Deus-Neumann, B.; Zenk, M. H. Phytochemistry 1998, 47, 375.

14. Drandarov, K. Tetrahedron Lett. 1995, 36, 617.

15. Guggisberg, A.; Drandarov, K.; Hesse, M. Helv. Chim. Acta 2000, 83, 3035.

16. Zenk, M. H.; Gerardy, R.; Stadler, R. J. Chem. Soc., Chem. Commun. 1989, 22, 1725.

17. Stadler, R.; Zenk, M. H. J. Biol. Chem. 1993, 268, 823.

18. Nezbedová, L.; Drandarov, K.; Werner, C.; Hesse, M. Helv. Chim. Acta 2000, 83, 2953.

19. Nezbedová, L.; Hesse, M.; Drandarov, K.; Werner, C. Tetrahedron Lett. 2000, 41, 7859.

20. Nezbedová, L.; Hesse, M.; Drandarov, K.; Bigler, L.; Werner, C. Planta 2001, 213, 411.

21. Kochs, G.; Grisebach, H. Z. Naturforsch. 1987, 42c, 343.

22. Guggisberg, A.; Prewo, R.; Hesse, M. Helv. Chim. Acta 1986, 69, 1012.

23. Werner, C.; Hu, W.; Lorenzi-Riatsch, A.; Hesse, M. Phytochemistry 1995, 40, 461.

24. Lumbu, S.; Hootele, C. J. Nat. Prod. 1993, 56, 1418.

25. Drandarov, K.; Guggisberg, A.; Hesse, M. 2001, in preparation.

26. Nezbedová, L.; Hesse, M.; Drandarov, K.; Werner, C. Helv. Chim. Acta 2001, 84, 172.

27. Deschamps, N. Inaugural-Dissertation, 2001, University of Zürich.

28. Werner, C.; Hedberg, C.; Lorenzi-Riatsch, A.; Hesse, M. Phytochemistry 1993, 33, 1033. 
29. Werner, C.; Petrini, O.; Hesse, M. FEMS Microbiology Lett. 1997, 155, 147. 